\section{A inclusão da odontologia no Programa Saúde da Família no Estado do Paraná, Brasil}

\author{
Inclusion of oral health services in the Family \\ Health Program in the State of Paraná, Brazil
}

Márcia Helena Baldani 1

Cristina Berger Fadel 1

Taisiane Possamai 1

Márcia Geny Schweitzer Queiroz ${ }^{1}$

\footnotetext{
1 Departamento de

Odontologia, Universidade Estadual de Ponta Grossa, Ponta Grossa, Brasil.

Correspondência M. H. Baldani Departamento de Odontologia, Universidade Estadual de Ponta Grossa. Av. Carlos Cavalcante 4748, Bloco M, Campus de Uvaranas, Ponta Grossa, $P R$ 84030-000, Brasil. marcia@convoy.com.br
}

\begin{abstract}
The aim of this study was to analyze the implementation of dental care in the Family Health Program (FHP) in the State of Paraná, Brazil, one year after Ministry of Health (MoH) Ruling 1,444 went into effect. A qualitative and quantitative study was designed, focusing on the 136 municipalities which had included oral health services in the program by early 2002. The dental care teams received previously tested questionnaires on administrative and operational issues. The mean population covered by each team is close to the minimum stipulated by the $\mathrm{MoH}$ in 2000. However, some teams experienced difficulties in developing all the activities under their responsibility. Referral of more complex cases was also reported as a critical point. Favorable reception by the population and participation by dentists in the training courses were identified as positive points. Finally, a large proportion of dentists were under temporary work contracts (37.7\%); there were also reports of the need to train general dental practitioners with an adequate profile for the FHP.
\end{abstract}

Oral Health; Dental Health Services; Family Health Program; Health Policy

\section{Introdução}

O grande desafio para a saúde pública consiste em propor programas de intervenção culturalmente sensíveis e adaptados ao contexto no qual vivem as populações às quais são destinados. O reconhecimento da crise do modelo assistencial predominante no Brasil, no âmbito da saúde coletiva, vem suscitando a emergência de propostas que visam à transformação do sistema de atenção em saúde, de suas práticas e, em articulação com essas, do processo de trabalho em saúde. Os anos 90 testemunharam grandes mudanças nas políticas de saúde no Brasil, norteadas pela necessidade de rupturas com as formas de organização do sistema de saúde, que teve seu ápice quando, em 1994, o Ministério da Saúde (MS) apresentou o Programa Saúde da Família (PSF) como estratégia para consolidação do SUS 1. Para Medina \& Aquino 2 , o programa tem se constituído num dos pilares desse movimento de mudanças, consolidando-se como política de governo.

O documento que define as bases do PSF 1 destaca que, em oposição ao modelo tradicional, centrado na doença e no hospital, prioriza as ações de proteção e promoção de saúde dos indivíduos e da família, tanto adultos quanto crianças, sadios ou doentes, de forma integral e contínua. Pode-se incluir ainda às bases desse modelo assistencial aspectos relativos à área de abrangência com adscrição da clientela, 
equipe multiprofissional com ações intersetoriais, ações programadas a partir de prioridades epidemiológicas e intensa participação comunitária. O envolvimento governamental em áreas prioritárias como educação, saneamento, alimentação, renda, moradia e segurança, torna-se fundamental para a construção do novo processo assistencial, possibilitando a adesão e mobilização das forças sociais e políticas em torno de suas diretrizes. Configura também, uma nova concepção de trabalho, com capacidade de formar vínculos e propor alianças, permitindo maior diversidade das ações e busca permanente do fortalecimento sistemausuário.

O PSF deve ter como lógica o rompimento da organização disciplinar tradicional, fragmentada e prioritariamente voltada para a dimensão biológica do processo saúde-doença, devendo dar condições para que médicos, cirurgiões-dentistas, psicólogos, nutricionistas, engenheiros e demais profissionais sejam capazes de estabelecer conexões entre conhecimentos específicos de cada profissão a fim de propor novas práticas 3 .

Infelizmente essa transsetorialidade não se constituiu em iniciativa governamental primeira, ao menos no que se refere à saúde bucal. Somente em dezembro do ano 2000, por intermédio da Portaria n. 1.444 do MS (Diário Oficial da União 2000; 29 dez), houve um incentivo para a reorganização da atenção à saúde bucal prestada à população brasileira, frente aos alarmantes resultados obtidos pela Pesquisa Nacional de Amostras por Domicílio (Instituto Brasileiro de Geografia e Estatística. Acesso e Utilização dos Serviços de Saúde: PNAD 1998. Rio de Janeiro; 2000), visando então a ampliação do acesso coletivo às ações de promoção, prevenção e recuperação da saúde bucal e a conseqüente melhoria de seus indicadores epidemiológicos.

O fato da odontologia não estar presente desde o início do programa possivelmente acarretou prejuízos no processo de integralização dos profissionais co-relacionados, assim como pode ter determinado formas variadas no processo de implantação das equipes de saúde bucal. Este estudo teve como objetivo analisar o perfil de implantação da Odontologia no PSF no Estado do Paraná, Brasil, um ano após a entrada em vigor da Portaria n. 1.444 do MS.

\section{Métodos}

Até início do ano 2002, 303 dos 399 municípios do Estado do Paraná haviam implantado o PSF sendo que, desses, 136 incorporaram equipes de saúde bucal ao programa. Este estudo, de natureza quali-quantitativa, envolveu todos os municípios que possuíam equipes de saúde bucal implantadas no PSF até esse período, segundo informações obtidas junto à Secretaria de Estado da Saúde do Paraná (SES-PR), que colaborou com a realização da pesquisa.

Dois tipos de questionários foram encaminhados aos municípios, acompanhados de um ofício no qual se descrevia a finalidade e objetivos da pesquisa. O pré-teste desses questionários aconteceu durante um dos cursos do Pólo de Capacitação do PSF da região de Ponta Grossa, Paraná, do qual participaram cerca de trinta cirurgiões-dentistas atuantes no programa. O primeiro deles abordava aspectos administrativos do PSF e solicitou-se que fosse respondido pelo Coordenador de Saúde Bucal ou Secretário Municipal da Saúde. Este continha questões relativas a: (a) início da atuação das equipes de saúde bucal; (b) número e modalidade das equipes de saúde bucal; (c) população coberta pelo PSF; (d) localização das unidades de saúde da família; (e) forma de contratação dos dentistas para atuarem nas equipe de saúde bucal; (f) faixa salarial dos dentistas, atendente de consultório dentário e técnico em higiene dental que atuam no programa; (g) jornada de trabalho desses profissionais. O outro abordava aspectos operacionais, deveria ser respondido por todos os dentistas que estivessem atuando no PSF, e apresentava questões sobre: (a) tempo de atuação no PSF; (b) participação em cursos de capacitação; (c) clientela atendida pela equipe de saúde bucal; (d) forma de agendamento dos pacientes em relação ao tratamento odontológico; (e) periodicidade de visitas domiciliares pelo dentista; (f) encaminhamento dos casos de maior complexidade; (g) ações desempenhadas pelo dentista e pessoal auxiliar; (h) envolvimento da equipe de saúde bucal com o restante da equipe de saúde da família; (i) periodicidade das reuniões entre toda a equipe de saúde da família, incluindo o pessoal de saúde bucal; (j) utilização ou não de prontuários únicos. Os dois tipos de questionários compreendiam perguntas objetivas (fechadas) e contavam com uma questão subjetiva (aberta) para que os participantes expressassem sua opinião sobre experiências, suces- 
sos ou dificuldades encontradas na operacionalização do programa.

Os dados foram submetidos à análise descritiva e os resultados expressos em médias, freqüências e proporções. O teste estatístico qui-quadrado foi aplicado para avaliar a associação do porte dos municípios com a implantação ou não do PSF e das equipes de saúde bucal.

\section{Resultados}

O Estado do Paraná contava, no primeiro semestre de 2002, com o PSF implantado em 303 de seus 399 municípios. A proporção de municípios que aderiram ao programa até o final de $2001(74,18 \%)$ era maior do que a daqueles que não aderiram $(25,82 \%)$, independente do porte demográfico dos mesmos (Tabela 1), indicando um padrão homogêneo de adesão quanto a esse aspecto. Dentre os municípios que implantaram o PSF, observou-se diferença para presença ou não das equipes de saúde bucal, e identificou-se um maior padrão de adesão por parte dos de pequeno porte demográfico (Tabela 2).

O presente estudo abrangeu a totalidade dos municípios paranaenses (136) que implantaram atenção à saúde bucal no PSF até o primeiro semestre de 2002, correspondendo a 278 equipes, sendo 66 em modalidade I (um cirurgião-dentista e um atendente de consultório dentário) e 39 em modalidade II (um cirurgiãodentista, um técnico em higiene dental e um atendente de consultório dentário), segundo dados disponibilizados pelo site da SES-PR.

Neste estudo, foram obtidas respostas de 77 municípios, correspondendo a 56,6\% dos questionários enviados. Do total de 278 cirurgiõesdentistas atuantes nas equipe de saúde bucal no Estado, 105 responderam (37,8\%). Não fo-

Tabela 1

Distribuição proporcional dos municípios do Estado do Paraná, Brasil, quanto à implantação ou não do Programa Saúde da Família (PSF), segundo o porte demográfico.

\begin{tabular}{|c|c|c|c|c|c|c|c|c|}
\hline \multirow[t]{2}{*}{ PSF } & \multicolumn{2}{|c|}{ Pequeno porte* } & \multicolumn{2}{|c|}{ Médio porte** } & \multicolumn{2}{|c|}{ Grande porte ${ }^{\star \star \star}$} & \multicolumn{2}{|c|}{ Total } \\
\hline & $\mathrm{n}$ & $\%$ & $\mathrm{n}$ & $\%$ & $\mathrm{n}$ & $\%$ & $\mathrm{n}$ & $\%$ \\
\hline Com & 172 & 79,63 & 106 & 69,74 & 25 & 80,65 & 303 & 74,18 \\
\hline Sem & 44 & 20,37 & 46 & 30,26 & 6 & 19,35 & 96 & 25,82 \\
\hline Total & 216 & 100,00 & 152 & 100,00 & 31 & 100,00 & 399 & 100,00 \\
\hline
\end{tabular}

* Até 10 mil habitantes;

** 10 mil a 50 mil habitantes:

$\star \star \star$ Mais de 50 mil habitantes;

$\mathrm{p}=0,07$

Tabela 2

Distribuição proporcional dos municípios do Estado do Paraná, Brasil, quanto à implantação ou não de equipes de saúde bucal (ESB) no Programa Saúde da Família (PSF), segundo o porte demográfico.

\begin{tabular}{|c|c|c|c|c|c|c|c|c|}
\hline \multirow[t]{2}{*}{ ESB } & \multicolumn{2}{|c|}{ Pequeno porte* } & \multicolumn{2}{|c|}{ Médio porte** } & \multicolumn{2}{|c|}{ Grande porte ${ }^{\star \star \star}$} & \multicolumn{2}{|c|}{ Total } \\
\hline & $n$ & $\%$ & $\mathrm{n}$ & $\%$ & $n$ & $\%$ & $\mathrm{n}$ & $\%$ \\
\hline Com & 93 & 54,07 & 33 & 31,13 & 10 & 40,00 & 136 & 45,96 \\
\hline Sem & 79 & 45,93 & 73 & 68,87 & 15 & 60,00 & 167 & 54,04 \\
\hline Total & 172 & 100,00 & 106 & 100,00 & 25 & 100,00 & 303 & 100,00 \\
\hline
\end{tabular}

* Até 10 mil habitantes;

** 10 mil a 50 mil habitantes:

$\star \star \star$ Mais de 50 mil habitantes;

$\mathrm{p}<0,001$. 
ram investigadas as causas de não resposta, sendo que o padrão obtido $(56,6 \%)$ pode ser considerado dentro do esperado para respostas em estudos que utilizam correspondências com uma única postagem ${ }^{4}$. Apesar disso, os resultados não permitem inferência para todo o Estado do Paraná.

Os dados indicam que grande parte das equipe de saúde bucal foi implantada no segundo semestre de 2001 (46,7\%) e no primeiro semestre de 2002 (32,5\%), sendo que apenas dois municípios - Catanduvas (população de 10.421 habitantes) e Pitanga (população de 2.418 habitantes) relataram ter inserido a odontologia no PSF antes de 2001. Dessa forma, o tempo médio de atuação no PSF pelos cirurgiões-dentistas que responderam ao questionário foi de oito meses, sendo que o tempo mínimo relatado foi menor que um mês e o máximo foi de dois anos de experiência em saúde da família. Com relação à localização das unidades de saúde da família, 73 municípios apresentaram unidades em região urbana, sendo que, desses, apenas 19 estenderam o programa à zona rural. Quatro municípios implantaram equipe de saúde bucal apenas na zona rural.

Os resultados relativos aos aspectos administrativos de funcionamento das equipes de saúde bucal estão relacionados na Tabela 3, na qual observa-se a forma de contratação dos cirurgiões-dentistas para atuarem no programa, bem como carga horária semanal e remuneração dos mesmos.

Outras estatísticas descritivas, obtidas com base nas informações contidas nos questionários e não apresentadas em tabelas, indicam que a média observada de população coberta por equipe ( $4.947 \pm 1.700$ pessoas), praticamente corresponde ao mínimo estipulado pela Portaria n. 1.444 do MS, que era de 4.800 habitantes/equipe de saúde bucal (equivalente à soma do mínimo indicado para duas equipes de saúde da família), em 2000. Ao se observar a distribuição dos dados por percentis, verificase que $65,0 \%$ das equipe de saúde bucal abrangem até 5 mil pessoas e $85,0 \%$ delas atendem a até 6.900 pessoas, que era o valor máximo estipulado por equipe pela Portaria.

A Tabela 4 apresenta as ações desenvolvidas pelos integrantes das equipes de saúde bucal neste estudo, bem como a clientela atendida pelo programa. As questões pertinentes a essas ações foram elaboradas baseando-se nas atribuições específicas a cada categoria profissional segundo a Portaria n. 1.444. Observa-se que todos os cirurgiões-dentistas estão basicamente envolvidos com o atendimento clínico, sendo que nem todos desenvolvem as outras
Tabela 3 Distribuição, segundo aspectos administrativos, da implantação
das equipes de saúde bucal no Programa Saúde da Família nos municípios
do Estado do Paraná, Brasil.

\begin{tabular}{|c|c|c|}
\hline Aspectos administrativos & $\mathbf{n}$ & $\%$ \\
\hline \multicolumn{3}{|l|}{ Forma de contratação dos cirurgiões-dentistas } \\
\hline Concurso público & 21 & 27,30 \\
\hline Teste seletivo interno & 18 & 23,40 \\
\hline Aproveitamento de pessoal sem teste seletivo & 6 & 7,80 \\
\hline Credenciamento & 10 & 13,00 \\
\hline Licitação & 7 & 9,10 \\
\hline Contrato de prestação de serviços & 10 & 13,00 \\
\hline Outros & 2 & 2,60 \\
\hline Sem resposta & 3 & 4,00 \\
\hline Total & 77 & 100,00 \\
\hline \multicolumn{3}{|l|}{ Jornada de trabalho da equipe de saúde bucal } \\
\hline 4 horas/dia (20 horas/semana) & 3 & 3,90 \\
\hline 6 horas/dia (30 horas/semana) & 2 & 2,60 \\
\hline 8 horas/dia (40 horas/semana) & 70 & 91,00 \\
\hline Sem resposta & 2 & 2,60 \\
\hline Total & 77 & 100,00 \\
\hline \multicolumn{3}{|l|}{ Faixa salarial dos cirurgiões-dentistas } \\
\hline Abaixo de R\$1.200 (US\$ 430) & 28 & 36,40 \\
\hline $\mathrm{R} \$ 1.201$ a $\mathrm{R} \$ 1.800$ (US\$ 431-US\$ 643) & 28 & 36,40 \\
\hline $\mathrm{R} \$ 1.801$ a $\mathrm{R} \$ 2.200$ (US\$ 643-US\$ 786) & 9 & 11,70 \\
\hline Mais de R\$2.201 (US\$ 787) & 10 & 12,90 \\
\hline Sem resposta & 2 & 2,60 \\
\hline Total & 77 & 100,00 \\
\hline
\end{tabular}

atividades. Os auxiliares, por sua vez, centram suas ações em atividades convencionais como instrumentação do cirurgião-dentista, e desinfecção e esterilização de materiais e instrumentais. Com relação à clientela atendida, observase que as populações menos assistidas correspondem aos bebês, gestantes e idosos.

A Tabela 5 apresenta alguns aspectos da operacionalização das atividades das equipes de saúde bucal, bem como do encaminhamento dos casos de maior complexidade.

\section{Discussão}

A partir do ano 2000, o PSF passou a ter maior adesão de municípios de médio e grande porte no Brasil, contrapondo com o que se verificou no início da implantação do programa no país, quando houve uma maior adesão por parte de municípios de pequeno porte 2 . Os resultados da Tabela 1 corroboram essa afirmação, uma 


\section{Tabela 4}

Distribuição segundo as ações desenvolvidas e clientela atendida pelos integrantes das equipes de saúde bucal no Programa Saúde da Família nos municípios do Estado do Paraná, Brasil (respostas múltiplas; $n=105$ ).

\begin{tabular}{|c|c|c|}
\hline Variável & $\mathbf{n}$ & $\%$ \\
\hline \multicolumn{3}{|l|}{ Ações desenvolvidas por cirurgiões-dentistas } \\
\hline Atendimento à demanda (clínico) & 105 & 100,00 \\
\hline Visita domiciliar & 93 & 88,60 \\
\hline Prevenção e promoção de saúde & 100 & 95,20 \\
\hline Reunião com toda a ESB & 84 & 80,00 \\
\hline Planejamento do trabalho & 96 & 91,40 \\
\hline Interação com outros setores & 76 & 72,40 \\
\hline Reunião com a comunidade de abrangência & 78 & 74,30 \\
\hline Estabelecimento de grupos prioritários & 77 & 73,30 \\
\hline Articulação de referência e contra-referência & 51 & 48,60 \\
\hline $\begin{array}{l}\text { Utilização do Sistema de Informação } \\
\text { da Atenção Básica para planejamento }\end{array}$ & 35 & 33,30 \\
\hline \multicolumn{3}{|c|}{$\begin{array}{l}\text { Ações desenvolvidas por auxiliares (técnico em } \\
\text { higiene dental e atendente de consultório dentário) }\end{array}$} \\
\hline Visita domiciliar & 72 & 68,60 \\
\hline Reuniões com a comunidade & 63 & 60,00 \\
\hline Agendamento dos pacientes & 97 & 92,40 \\
\hline Prevenção e promoção da saúde & 87 & 82,90 \\
\hline Instrumentação do cirurgião dentista & 101 & 96,20 \\
\hline Desinfecção e esterilização de instrumental & 104 & 99,00 \\
\hline \multicolumn{3}{|l|}{ Grupos populacionais atendidos } \\
\hline Gestantes & 86 & 81,90 \\
\hline Bebês (0-3 anos) & 79 & 75,20 \\
\hline Pré-escolares (4-6 anos) & 96 & 91,40 \\
\hline Escolares (7-12 anos) & 97 & 92,40 \\
\hline Adolescentes (13-19 anos) & 99 & 94,30 \\
\hline Adultos (20-59 anos) & 98 & 93,30 \\
\hline Idosos (60 anos ou mais) & 92 & 87,60 \\
\hline
\end{tabular}

vez que demonstram que, no Estado do Paraná, a adesão ao PSF no final de 2001 era significativamente maior do que a não adesão, independente do porte demográfico dos municípios. O mesmo pode-se dizer dos resultados da Tabela 2, os quais demonstram que existem diferenças significativas para a proporção de municípios que incorporaram ou não a odontologia ao PSF segundo seu porte demográfico, notando-se uma menor adesão daqueles de médio e grande porte, após um ano de vigência da Portaria n. 1.444.

Deve-se considerar que, em relação ao porte municipal, os cenários de instalação do PSF e das equipes de saúde bucal não parecem ser distintos. Medina \& Aquino 2 explicam que para o PSF, em municípios pequenos, altas cober- turas populacionais (e conseqüentemente maior incentivo financeiro por equipe) podem ser obtidas com a instalação de pequeno número de equipes, significando para muitos deles, expansão de serviços básicos. Ainda segundo os autores, para os municípios maiores a adoção do PSF parece exigir um esforço de reorganização do sistema de saúde, uma vez que, nesses, geralmente já existe uma rede física instalada e um conjunto de profissionais atuando numa determinada lógica de organização dos serviços.

O presente estudo obteve, após uma única postagem dos questionários, $56,6 \%$ de respostas dos municípios. Considerou-se esse número de respostas suficiente, uma vez que houve uma distribuição geográfica uniforme dos municípios respondentes em relação aos não respondentes, e manteve-se uma proporcionalidade adequada considerando-se o porte demográfico dos mesmos. Do total de 278 equipes de saúde bucal, 105 (37,8\%) responderam o questionário. Esse número, apesar de pequeno, pode ser considerado representativo do estado, uma vez que, do total de equipes existentes, 90 pertencem ao Município de Curitiba, pioneiro na inserção da odontologia no PSF no Brasil 5, e que não retornou o questionário. Então, excluindo esse município que, por suas características, tem sido alvo de estudos específi$\cos 5,6$, e considerando as 188 equipes restantes, distribuídas pelo território, o total de respostas passa a representar $55,85 \%$ dos dentistas atuantes no PSF no Estado do Paraná. Mesmo assim, não se pode extrapolar os resultados aqui obtidos para todo o estado, uma vez que existe a possibilidade de que os municípios que não retornaram o questionário apresentem características distintas daqueles que responderam.

Uma questão bastante discutida na atualidade diz respeito ao mercado de trabalho que se abriu para a categoria odontológica com a implantação da saúde bucal no PSF. Os resultados relativos aos aspectos administrativos de funcionamento das equipes de saúde bucal estão relacionados na Tabela 3, na qual observa-se a forma de contratação dos cirurgiões-dentistas para atuarem no programa, bem como carga horária semanal e remuneração dos mesmos.

Machado 7 indica que existem diversas modalidades possíveis de contratação de profissionais para o PSF, além do tradicional concurso público (que demanda a criação de novos cargos efetivos): convênio com organizações não-governamentais (ONG) ou cooperativas; contrato com empresas, por meio de licitação (terceirização); contrato temporário, renovável 
por até quatro anos; e cargos em comissão, estabelecendo vínculo temporário com a administração pública. Os resultados deste estudo demonstram que, no Paraná, $27,3 \%$ dos odontólogos foram contratados por meio de concurso público, $31,2 \%$ foram remanejados de outras unidades de saúde do próprio município e $37,7 \%$ foram contratados de maneira informal mediante credenciamentos, licitações, contratos de prestação de serviços e outros, sendo que praticamente todos cumprem jornadas de 40 horas semanais $(91,0 \%)$. O porte demográfico dos municípios não esteve relacionado com as formas de contratação dos profissionais.

Machado 7, ao traçar o perfil de médicos e enfermeiros atuantes no PSF no Brasil em 2000, encontrou um resultado semelhante ao deste estudo: $40,5 \%$ dos médicos e $38,9 \%$ dos enfermeiros relataram que atuam por meio de contratos temporários. A autora comenta que essa flexibilização das relações de trabalho verificada no programa, aliada à grande oferta de vagas nos vários municípios, resultam em freqüentes mudanças dos profissionais, o que compromete a continuidade do programa, principalmente no que diz respeito à relação com a comunidade e a credibilidade do mesmo. Com ela concorda Conill 8 ao analisar o PSF em Florianópolis, Santa Catarina, entre 1994 e 2000. A autora indica que existe um consenso quanto ao fato de que os recursos humanos constituem uma problemática central no programa, tanto no que diz respeito à sua contratação (recrutamento), quanto à capacitação, motivação, supervisão e rotatividade de profissionais.

Machado 7 ainda acrescenta que a precarização do trabalho, com perdas substantivas de garantias trabalhistas são fortemente observadas no PSF. Tal fato pode ser verificado ao observar-se os resultados deste estudo, mostrando-se evidente no depoimento de um dos cirurgiões-dentistas, contratado por licitação (aqui não se referindo à licitação de empresas, mas sim dos próprios profissionais, ou seja, de pessoas): "não temos direitos trabalhistas. Em geral o PSF nos municípios exige muito dos dentistas, mas não pensa em seus direitos!". Esse "aviltamento" das relações trabalhistas não seria tão relevante e grave se o PSF não fosse governamental, instituído pelo governo federal, e expandido para os estados e municípios, onde imagina-se e espera-se que a observância das garantias trabalhistas sempre tenha sido, historicamente, preservada 7 .

Um fato freqüentemente observado nas respostas dos cirurgiões-dentistas relacionou-se com a discrepância que existe entre os salários dos médicos e enfermeiros com os dos odon-
Tabela 5

Distribuição, segundo aspectos operacionais, das equipes de saúde bucal no Programa Saúde da Família nos municípios do Estado do Paraná, Brasil.

\begin{tabular}{|c|c|c|}
\hline Aspectos operacionais & $\mathbf{n}$ & $\%$ \\
\hline \multicolumn{3}{|l|}{ Forma de agendamento das consultas } \\
\hline $\begin{array}{l}\text { Nas residências (agentes comunitários } \\
\text { de saúde ou equipes de saúde bucal) }\end{array}$ & 11 & 10,50 \\
\hline $\begin{array}{l}\text { Nas unidades de saúde da família (atendente } \\
\text { de consultório dentário, técnico em higiene } \\
\text { dental, auxiliar de enfermagem) }\end{array}$ & 34 & 32,40 \\
\hline Nas residências e nas unidades de saúde da família & 45 & 42,90 \\
\hline Livre demanda como porta de entrada & 10 & 9,50 \\
\hline Outras formas & 1 & 0,90 \\
\hline Sem resposta & 4 & 3,80 \\
\hline Total & 105 & 100,00 \\
\hline \multicolumn{3}{|l|}{$\begin{array}{l}\text { Periodicidade de visitas domiciliares } \\
\text { pelos cirurgiões-dentistas }\end{array}$} \\
\hline Nunca (não sobra tempo) & 8 & 7,60 \\
\hline Semanalmente & 30 & 28,60 \\
\hline Quinzenalmente & 7 & 6,70 \\
\hline Mensalmente & 14 & 13,30 \\
\hline A cada dois meses & 3 & 2,90 \\
\hline Sempre que necessário & 41 & 39,00 \\
\hline Outros & 2 & 1,90 \\
\hline Total & 105 & 100,00 \\
\hline \multicolumn{3}{|l|}{ Encaminhamento de maior complexidade } \\
\hline Centro de referência no próprio município & 26 & 24,80 \\
\hline Centro de referência em município próximo e maior & 45 & 42,90 \\
\hline $\begin{array}{l}\text { Centro de referência no próprio município } \\
\text { e em município próximo e maior }\end{array}$ & 8 & 7,60 \\
\hline $\begin{array}{l}\text { Não são encaminhados e são resolvidos na própria } \\
\text { unidade de saúde da família }\end{array}$ & 10 & 9,50 \\
\hline Não são encaminhados e não são resolvidos & 10 & 9,50 \\
\hline Consultórios particulares & 1 & 0,90 \\
\hline Não especificou & 5 & 4,80 \\
\hline Total & 105 & 100,00 \\
\hline
\end{tabular}

tólogos. Na Tabela 3 observa-se a distribuição salarial dessa categoria, em Reais e em Dólares (com cotação em julho de 2002). Ao compararse a renda média relatada por médicos e enfermeiros no PSF 7, fica evidente essa desproporção: enquanto a renda média salarial dos médicos é de US\$2.229 e dos enfermeiros, de US\$ 1.123 , o presente estudo indicou que $72,8 \%$ dos cirurgiões-dentistas recebem até 643 dólares e, desses, metade recebe até 430 dólares mensais.

Um outro tópico destacado nos relatos dos gestores e cirurgiões-dentistas que responderam os questionários diz respeito ao financiamento da saúde bucal no PSF, bem como o en- 
volvimento de gestores (estaduais e municipais) com uma real implementação do programa. Marques \& Mendes 9, indicam que, com a implantação de programas como o PSF, houve um incremento de recursos do MS alocados à atenção básica, transferidos mediante o Piso de Atenção Básica (PAB) variável, o qual passou a incorporar diferentes incentivos que "premiam" os municípios que desenvolvem os programas sugeridos. Para os autores, o financiamento do PSF é problemático e instável 9 , principalmente do ponto de vista dos municípios, uma vez que o volume de recursos de origem municipal passível de ser destinado ao programa é muito variável e, geralmente, escasso. Há que se considerar ainda que, do ponto de vista do PSF, existe uma espécie de "discriminação positiva" por parte do governo federal no sentido de aumentar o valor de repasse anual em virtude de maior cobertura populacional, fato que não ocorre com os incentivos destinados à saúde bucal (Portaria n. 1.444). O valor anual pago por equipe é de $\mathrm{R} \$ 15.600,00$ para modalidade I e R\$ 19.200,00 para a modalidade II (Portaria $n$. 673. Atualiza e revê o incentivo financeiro às ações de saúde bucal no âmbito do Programa Saúde da Família, parte integrante do Piso de Atenção Básica. Diário Oficial da União 2003; 3 jun). A esses valores acresce-se um incentivo adicional de $\mathrm{R} \$ 5.000,00$ por nova equipe de saúde bucal instalada.

A carência de recursos foi bastante abordada nos relatos obtidos no presente estudo: faltam recursos financeiros, estruturais, físicos e humanos. Observou-se principalmente a dificuldade de obter-se recursos junto aos gestores municipais, como pode ser percebido no depoimento de um dentista: "acho que deveria haver alguma forma de explicar melhor aos chefes e prefeitos que a verba do PSF é só um incentivo, não que eles devam utilizar só aquela quantia para manter o programa, seria um suplemento". Por sua vez, um gestor municipal, ao referir-se à pequena participação do Estado na distribuição de recursos financeiros aos municípios comenta: "a dificuldade é que o Estado não aplica qualquer recurso financeiro no PSF, tanto no médico quanto no bucal. Ese auto proclama fiscalizador do dinheiro alheio...". Marques \& Mendes 9 relatam que poucos estados brasileiros têm destinado recursos financeiros aos municípios para a instalação do PSF, sendo que o Paraná é um dos que têm contribuído. Segundo esses autores, em levantamento realizado no Departamento de Atenção Básica, MS em junho de 2001, o Paraná encaminhou aos municípios kits contendo material médico. Quanto à participação do Estado, a
Portaria n. 267 do MS (Estabelece normas e diretrizes de inclusão da saúde bucal no Programa Saúde da Família. Diário Oficial da União 2001; 6 mar) estabelece como responsabilidade institucional deste, dentre outras, prestar assessoria técnica aos municípios em todo o processo de implantação, planejamento, monitoramento e gerenciamento das ações de saúde bucal no PSF. Também faz parte do conjunto de suas atribuições realizar capacitação técnica e educação permanente específica para os profissionais por meio dos pólos de capacitação, formação e educação permanente. Esse papel parece estar sendo bem conduzido pela SESPR por meio de cursos específicos para os profissionais de saúde bucal 10. Corrobora esse fato a informação coletada neste estudo: $94,3 \%$ dos cirurgiões-dentistas relataram ter participado de cursos de capacitação, sendo que os que não participaram relataram que tinham sido recém-contratados.

Analisando o número médio de pessoas atendidas por equipe de saúde bucal neste estudo, nota-se que apenas $15,0 \%$ dos municípios relataram que suas equipes detêm uma população adscrita maior do que o máximo recomendado pelo MS (Portaria n. 1.444). Apesar disso, observa-se que existe dificuldade, por parte de algumas equipes, em desempenhar todas as atividades pertinentes a elas como, por exemplo, visitas domiciliares pelo dentista, ações de prevenção e promoção à saúde, bem como reuniões com a comunidade de abrangência (Tabelas 4 e 5), o que significa que, mesmo com a introdução de uma relação equipe de saúde bucal/equipe de saúde da família de 1:1 a partir de junho de 2003 (Portaria n. 673), as dificuldades provavelmente continuarão a ocorrer.

As dificuldades em atender a demanda da população adscrita às equipes de PSF também foram relatadas por Conill 8 (p. 197), referindose apenas ao trabalho médico. No presente estudo o depoimento de um dos cirurgiões-dentistas traduz esse mesmo problema: "pela precariedade sócio-econômica da população os casos que necessitam tratamento são inúmeros, dificultando a disponibilização da equipe de saúde bucal para ações preventivas e de promoção de saúde. Estamos como bombeiros a apagar incêndios".

Ainda com relação à Tabela 4 , uma observação importante é de que os bebês, gestantes e idosos, nessa seqüência, são os grupos populacionais menos atendidos pelas equipes, demonstrando que, na área de saúde bucal, ainda não se cumpriu um dos objetivos do PSF, que é estender a atenção a todas as pessoas da comunidade. Com relação aos bebês, deve-se con- 
siderar que grande número de municípios do estado aderiu ao Programa de Atenção Precoce à Saúde Bucal 11, e possui clínicas de bebês para onde esses possivelmente vêm sendo encaminhados.

Analisando a Tabela 4, nota-se que tanto os cirurgiões-dentistas quanto os auxiliares estão basicamente envolvidos com atividades clínicas. Essa dificuldade de escapar do modelo de atenção tradicional reflete-se no seguinte comentário: "um dentista apenas para duas equipes de saúde da família não funciona, pois o mesmo volta a ser um dentista clínico de unidade básica de saúde normal, não tendo tempo de atuar com a família, como o próprio nome diz, deixando de ser PSF".

Quanto à metodologia de trabalho dos profissionais das equipes de saúde bucal, convém ressaltar ainda as dificuldades decorrentes de sua própria formação profissional tecnicista e hospitalocêntrica. Esse problema vem sendo observado nas equipes de PSF de maneira geral 8,12,13 e, neste estudo, por meio do depoimento de um dos cirurgiões-dentistas: "no PSF o profissional não pode examinar apenas um órgão em especial, e sim, ter uma noção geral do paciente, coisa que dificilmente se aprende no período de graduação na faculdade". Atualmente, já existe exigência por parte do Ministério da Educação e Cultura, mediante novas diretrizes curriculares para os cursos da área da saúde, de que a graduação vise à formação de profissionais generalistas, que tenham um perfil adequado para atuar no PSF. Esse perfil pôde ser observado nos depoimentos de alguns dos odontólogos que demonstram claramente o processo de humanização da atenção: “o nosso vínculo humano aumentou, não tratamos dentes, mas pessoas. Troco muitas informações sobre a saúde geral e outras com a enfermeira...". "Apesar de os agentes comunitários de saúde serem o principal vínculo entre o profissional e a comunidade, acredito que as visitas domiciliares realizadas pelas equipes de saúde bucal têm grande importância, pois além de levarmos informações até as casas, podemos conhecer a realidade em que vivem".

Observa-se que o acesso ao serviço odontológico dentro do PSF é uma das dificuldades presentes em algumas equipes (Tabela 5). Notou-se que em $85,8 \%$ dos relatos, as consultas odontológicas são agendadas nas residências dos usuários ou na própria unidade de saúde da família. Por outro lado, porém, verificou-se que $9,5 \%$ das equipe de saúde bucal admitiram que a livre demanda é a porta de entrada para o atendimento odontológico, o que demonstra a dificuldade de adaptação à nova lógica de atenção proposta pelo PSF. Mesmo assim, pode-se notar através de alguns relatos que o programa tem contribuído para garantir uma maior satisfação do usuário, quer pela maior proximidade com os profissionais de saúde, quer pela maior facilidade de acesso aos serviços: “a população aprovou as visitas domiciliares, somos ajudados pela própria comunidade. Esta nos cede suas residências para utilização em palestras nas microáreas". "Observamos uma satisfação do usuário, com oportunidades de acesso às pessoas mais carentes e também a diminuição das filas...".

Na Tabela 5 também observam-se informações relativas ao encaminhamento dos casos de maior complexidade, os quais, em $75,3 \%$ dos municípios são encaminhados para centros de referência, nos próprios municípios ou em municípios próximos e maiores. Em 9,5\% dos municípios esses casos não são referenciados, porém são solucionados pelas próprias equipes; e em outros $9,5 \%$ não são resolvidos e nem encaminhados. Apesar de poucos municípios relatarem dificuldades para referenciar os casos mais complexos (21 no total), segundo Conill 8, para estes as dificuldades são agravadas ainda mais quando do dimensionamento inadequado entre equipe e população. Com isso, o tempo torna-se um impedimento à realização do menos complexo. Havendo problemas na referência para especialidades, o mais complexo também se torna mais difícil.

Com relação à interdisciplinaridade, 87,6\% dos dentistas relataram haver envolvimento entre a equipe odontológica e o restante da equipe de saúde da família. Mesmo assim, os dados indicam que essa aproximação é pequena, sendo que apenas $12,4 \%$ desses relatam reuniões semanais com toda a equipe (equipe de saúde bucal e equipe de saúde da família), $42,9 \%$ relatam reuniões mensais e $25,7 \%$ realizam reuniões esporádicas. Outra informação que pode indicar a pequena aproximação entre as equipes é o fato de que apenas $29,5 \%$ das unidades de saúde da família utilizam prontuários únicos para os pacientes. Finalmente, o relato de um dos cirurgiões-dentistas permite verificar a dimensão dessa questão: “a ausência do médico em tempo maior e muitas vezes a falta de programação efetiva das enfermeiras que são responsáveis pela programação das agentes, faz com que os serviços de odontologia sejam executados de forma unilateral, com programação exclusiva, contrariando o princípio de coletividade no objetivo de promoção de saúde". Quanto a esse aspecto, Pedrosa \& Teles 12 observaram em um estudo sobre o PSF em Teresina, Piauí, que o pequeno relacionamento in- 
terno da equipe estudada revelou a inexistência de responsabilidade coletiva pelos resultados do trabalho, levando à descontinuidade entre as ações específicas de cada profissional, observando-se desarticulação entre ações curativas, educativas e administrativas, bem como um baixo grau de interação entre os membros da equipe. Os resultados observados no presente estudo sugerem que investigações detalhadas sobre o processo de interdisciplinaridade merecem ser conduzidas.

\section{Resumo}

O objetivo deste estudo foi analisar o perfil de implantação da Odontologia no Programa Saúde da Família (PSF) no Estado do Paraná, Brasil, um ano após a entrada em vigor da Portaria n. 1.444 do Ministério da Saúde (MS). Para tanto, delineou-se um estudo qualiquantitativo que envolveu os 136 municípios que tinham implantado Equipes de Saúde Bucal no PSF até o início de 2002. Foram encaminhados questionários previamente testados, abordando aspectos administrativos e operacionais relacionados às equipes. Os resultados revelam que a média da população coberta por equipe corresponde ao mínimo estipulado pelo MS em 2000. Apesar disso, essas têm dificuldades em desempenhar todas as atividades pertinentes a elas. $O$ encaminhamento dos casos de maior complexidade também foi referido como ponto crítico. A recepção favorável por parte da população e a participação dos dentistas entrevistados em cursos de capacitação foram pontos positivos relatados. Finalmente, verificouse que o número de contratos temporários de dentistas não é pequeno $(37,7 \%)$ e os relatos indicam que há necessidade de formação de profissionais generalistas com perfil adequado para o PSF.

Saúde Bucal; Serviços de Saúde Bucal; Programa Saúde da Família; Política de Saúde

\section{Considerações finais}

Este estudo abordou alguns aspectos da implantação da odontologia no PSF no Estado do Paraná. Por meio de seus resultados pôde-se observar que os principais problemas e dificuldades que vêm sendo vivenciados pelas equipes de saúde bucal não são exclusivos da odontologia enquanto campo da saúde, mas refletem o que se apresenta na implementação do PSF como um todo. Não se pretende com este estudo esgotar o assunto, mas sim apontar caminhos que possam contribuir para a consolidação da saúde bucal no PSF, principalmente através do estímulo para que novos trabalhos sejam feitos sobre este tema.

\section{Colaboradores}

M. H. Baldani e C. B. Fadel delinearam o estudo, orientaram a elaboração e aplicação dos questionários, bem como redigiram o artigo. T. Possamai e M. G. S. Queiroz elaboraram e aplicaram os questionários. Os dados foram tabulados e analisados por M. H. Baldani.

\section{Agradecimentos}

Este trabalho contou com o apoio da Secretaria de Estado da Saúde do Paraná. 


\section{Referências}

1. Fundação Nacional de Saúde. Saúde dentro de casa: Programa Saúde da Família. Brasília: Fundação Nacional de Saúde; 1994.

2. Medina MG, Aquino R. Avaliando o Programa Saúde da Família. In: Sousa MF, organizador. Os sinais vermelhos do PSF. São Paulo: Editora Hucitec; 2002. p. 135-51.

3. Rabello SB, Corvino MPF. A inserção do CD no Programa Saúde da Família. Rev Bras Odontol 2001; 58:266-7.

4. Peres MAAP, Narvai PC, Calvo MCM. Prevalência de cárie dentária em crianças aos doze anos de idade, em localidades do Estado de São Paulo, Brasil, período 1990-1995. Rev Saúde Pública 1997; 31:594-600.

5. Moysés SJ. Os dizeres da boca em Curitiba: Boca Maldita, Boqueirão, bocas saudáveis. Rio de Janeiro: Centro Brasileiro de Estudos de Saúde; 2002.

6. Roncalli AG. A organização da demanda em serviços públicos de saúde bucal [Tese de Doutorado]. Araçatuba: Faculdade de Odontologia, Universidade Estadual Paulista; 2000.

7. Machado MH. Programa Saúde da Família no Brasil - algumas considerações sobre o perfil dos médicos e enfermeiros. In: Sousa MF, organizador. Os sinais vermelhos do PSF. São Paulo: Editora Hucitec; 2002. p. 125-32.
8. Conill EM. Políticas de atenção primária e reformas sanitárias: discutindo a avaliação a partir da análise do Programa Saúde da Família em Florianópolis, Santa Catarina, Brasil, 1994-2000. Cad Saúde Pública 2002; 18 Suppl:191-202.

9. Marques RM, Mendes A. A dimensão do financiamento da atenção básica e do PSF no contexto da saúde - SUS. In: Sousa MF, organizador. Os sinais vermelhos do PSF. São Paulo: Editora Hucitec; 2002. p. 71-104.

10. Merci JD. Capacitação para profissionais de saúde bucal na estratégia de saúde da família no Paraná. Revista Brasileira de Odontologia em Saúde Coletiva 2002; 3 Suppl Especial:96.

11. Baldani MHP, Lopes CMD, Kriger L, Matsuo T.A Odontologia para bebês no Estado do Paraná, Brasil - perfil do Programa de Atenção Precoce à Saúde Bucal. J Bras Odontopediatr Odontol Bebê 2003; 6:210-6.

12. Pedrosa JTS, Teles JBM. Consenso e diferenças em equipes do Programa Saúde da Família. Rev Saúde Pública 2001; 35:303-11.

13. Sousa MF. Os sinais vermelhos do PSF. São Paulo: Editora Hucitec; 2002.

Recebido em 06/Mai/2004

Versão final reapresentada em 22/Dez/2004

Aprovado em 27/Jan/2005 